\title{
Analysis of the relationship between physical activity and metabolic syndrome risk factors in adults with intellectual disabilities
}

\author{
Ji-Youn Kim, Eun-Surk Yi* \\ Exercise Rehabilitation Convergence Institute, Gachon University, Incheon, Korea
}

The purpose of this study was to investigate the relationship between physical activities and metabolic syndrome risk factors in adults with intellectual disabilities. Seventeen adults with intellectual disabilities at a sheltered workshop wore Actical for 5 days on workdays to measure their physical activity, and blood samples were taken to measure their physical fitness factors and examine their risk factors for metabolic syndrome. The average daily physical activity was found to be $655.41 \pm$ $129.36 \mathrm{kcal}$, and the average total physical activity over 5 days was $3,224.94 \pm 149.68 \mathrm{kcal}$. A positive correlation was confirmed between physical activity and muscular strength, muscular endurance, total cholesterol, low-density lipoprotein cholesterol and disability rating. Factors that predicted physical activity of adults with disabilities were disability rating $(t=6.280, P<0.001)$ and glycated hemoglobin $(t=-2.315, P<0.036)$, which had a $73.9 \%$ correlation $\left(R^{2}=0.739\right)$ with the physical activities of adults with intellectual disabilities. In conclusion, the physical activity level of adults with intellectual disabilities was significantly lower than that of adults in similar age groups, and such low physical activity may affect their muscular strength, muscular endurance, and metabolic syndrome risk factors. Therefore, additional studies on programs to improve and enhance physical activities at sheltered workshops, where adults with intellectual disabilities are mainly supervised and active, and guidelines for continuous health management are needed.

Keywords: Intellectual disabilities, Physical activity, Metabolic syndrome risk factors, Adults

\section{INTRODUCTION}

The number of intellectually disabled people in Korea is reported as 201,000 as of 2017 (Ministry of Health and Welfare, 2018). Intellectual disability is generally characterized as delayed verbal development, lack of understanding the concept of numbers, and slow daily self-care processes such as using the toilet, as well as emotional instability or abnormal behavior. In addition, balancing, separating, and connecting movements are not made correctly and walking speed is noticeably slower, restricting these people physically or environmentally, which leads to insufficient physical activity (Frey et al., 2008). As a result, intellectually disabled people are restricted in their ability to participate in active physical activities due to cognitive impairment, and their appetite is high- er than that of normal people, making it difficult for them to maintain a normal weight and resulting in an increased obesity rate.

This lack of physical activity is related to the increased prevalence of various chronic diseases such as hypertension, diabetes, hyperlipidemia, and arteriosclerosis, so management through active physical activity is important. In particular, physical activity is known to improve physical strength and lower the prevalence of chronic diseases such as hypertension, obesity, stroke, and diabetes (Taylor, 2014). It increases high-density lipoprotein (HDL), an antiatherosclerotic factor, and lowers low-density lipoprotein (LDL) through lipoprotein lipid metabolism to bring a positive effect to the blood lipid profile (Fernandes et al., 2018; Nelson et al., 2007).

In addition to intellectual deficits, intellectually disabled peo-

\footnotetext{
${ }^{*}$ Corresponding author: Eun-Surk Yi iD https://orcid.org/0000-0002-9370-5231 Department of Exercise Rehabilitation \& Welfare, Gachon University, 191 Hombakmoe-ro, Yeonsu-gu, Incheon 21936, Korea Tel: +82-32-820-4442, Fax: +82-32-820-4449, E-mail: yies@gachon.ac.kr Received: June 12, 2018 / Accepted: June 15, 2018
}

This is an Open Access article distributed under the terms of the Creative Commons Attribution Non-Commercial License (http://creativecommons.org/licenses/by-nc/4.0/) which permits unrestricted non-commercial use, distribution, and reproduction in any medium, provided the original work is properly cited. 
ple are typically reported to have higher blood pressure (Giordano et al., 2001) and blood sugar (Haider et al., 2013), the metabolic syndrome indexes, than nondisabled people. Therefore, ways to proactively increase their physical activity level are urgently needed to prevent chronic preventable and treatable diseases.

Hartman et al. (2015) stated that increased physical activity brought positive changes to body composition, and although different studies report the positive effects of physical activity participation and awareness of its importance is increasing, physical activity and participation by children with intellectual disabilities is reported to be very low (Cervantes and Porretta, 2010); few studies have been conducted that directly measure physical activity in these populations.

In particular, the physical activity level of intellectually disabled people in adulthood is similar to that of the elderly, causing serious problems in health and social costs (Dixon-Ibarra et al., 2013). Proper physical activity is closely related to independent life and quality of life of intellectually disabled people in adulthood, and therefore, different studies to promote their physical activity need to be conducted and applied in life.

Increased physical activity including movement of the entire body may serve as the solution to lower the risk of chronic diseases in children with intellectual disabilities due to lack of physical activity. For this, their physical activity needs to be measured and analyzed, and the results of long-term efforts to increase physical activity should be compared against people whose activity level has remained low to examine whether increased physical activity can bring changes to metabolic syndrome risk factors for children with intellectual disabilities.

Methods to measure physical activity have included surveys, daily logs, heart rate monitors, doubly labeled water, and pedometers, but it is difficult to apply these methods to disabled people. There have recently been studies to examine the physical activity level of children with disabilities using an accelerometer (Moss and Czyz, 2018), but studies targeting adults with disabilities are very rare. Therefore, this study intends to measure the physical activity of adults with disabilities using an accelerometer to confirm the relationship of their activity levels with biochemical variables and examine variables that can predict physical activities to provide basic data for use in exercises and programs to improve the physical activity levels of disabled adults.

\section{MATERIALS AND METHODS}

Consent to data collection was obtained from a sheltered work- shop in Uiwang and a survey of general characteristics and health characteristics was conducted on adults over 20 years of age with disabilities during the month of November, 2017. The name, age, sex, weight, and height of participants were entered into the Actical (Mini Mitter Inc., Bend, OR, USA), an accelerometer that the participants were instructed to wear for 5 weekdays and return. They were also instructed to fast until 8 a.m. on the day that they returned the Actical, give a blood sample, and go home. Breakfast was provided to participants after taking the blood sample, and their physical activity pattern was explained to them based on the physical activity record that was printed out from the Actical record.

\section{Subjects}

The subjects of this study included participants between the ages of 18-60 registered at 1 sheltered workshop in Uiwang with IQs between 45-70 who were able to communicate and did not have musculoskeletal system disorders or neurological damage. The purpose and measurement method of the study were explained to subjects and their guardians, who voluntarily signed the participation consent form.

\section{Tools}

Measurement of daily physical activity was done using an Actical. Participants were instructed to wear the accelerometer for 7 consecutive days to measure their activity levels on weekdays and weekends. Subjects were guided to perform daily physical activities freely to accurately measure their activity levels. They wore the Actical on their wrists using straps.

The product consisted of an Actical Sense, Acti-Reader, and computer software, and the Acti-Reader included a PC serial port interface, which facilitated telemetric data and transferred it from the Actical. Subjects' name, age, sex, weight, and height were downloaded to the Actical Sense using the Acti Reader, and the Actical Sense was worn on the wrist, ankle, or waist. The daily life or specific exercise record that was saved in the Actical was imported using the Acti Reader and analyzed on the computer. The duration of Actical use was 5 weekdays due to the nature and care of the disabled.

Muscular strength was measured using a digital dynamometer (TKK, Takei, Niigata, Japan), with measurements taken twice on each hand and the highest value recorded. To test muscular endurance, subjects did sit-ups for $1 \mathrm{~min}$ and their counts were recorded. Flexibility was measured using sit-and-reach equipment, starting at $-20 \mathrm{~cm}$ and pushing the equipment with both hands. 
For cardiovascular endurance, a 16-m Progressive Aerobic Cardiovascular Endurance Run was used, where subjects were instructed to run $16 \mathrm{~m}$ forward at the buzzer sound and reach the starting point on the opposite side prior to the next buzzer sound, then run at the next buzzer sound. The number of runs that they did upon buzzer sounds was recorded.

\section{Blood tests}

All subjects fasted for over $12 \mathrm{hr}$ prior to the test, and about 10 $\mathrm{mL}$ of blood was taken from the antebrachial vein at 8 a.m. the following day. Blood samples were analyzed for glycated hemoglobin $\left(\mathrm{HbA}_{\mathrm{lc}}\right)$, total cholesterol, LDL, and HDL using a chemical analyzer. LDL, HDL, total cholesterol, and neutral fat during fasting were measured through an enzymatic colorimetric assay using an automatic analyzer (Olympus Au 5200, Olympus, Tokyo, Japan).

\section{Data processing}

Collected data was analyzed to determine the mean, standard deviation, and range of subjects' physical activity, physical fitness, and metabolic syndrome index $\left(\mathrm{HbA}_{1 \mathrm{c}}\right.$, total cholesterol, LDL, and HDL). The correlation between subjects' physical activity and variables was analyzed using Pearson correlation, and variables that predicted the physical activity of disabled people were analyzed using stepwise multiple regression. Standard deviation was set at 0.05 .

Table 1. Differences in daily activity according to general characteristics (kcal)

\begin{tabular}{lcc}
\hline Characteristic & Mean \pm SD & $P$-value \\
\hline Age $(\mathrm{yr})$ & $29.88 \pm 7.50$ & \\
Height $(\mathrm{cm})$ & $168.53 \pm 7.75$ & \\
Weight $(\mathrm{kg})$ & $65.76 \pm 11.20$ & 0.410 \\
Body mass index $\left(\mathrm{kg} / \mathrm{m}^{2}\right)$ & & \\
$18.5-22.9(\mathrm{n}=9)$ & $528.33 \pm 97.67$ & \\
$23-24.9(\mathrm{n}=3)$ & $431.67 \pm 68.41$ & \\
$25-29.9(\mathrm{n}=2)$ & $406.50 \pm 149.20$ & \\
$30-39.9(\mathrm{n}=3)$ & $503.00 \pm 158.78$ & \\
Sex & & \\
Male $(\mathrm{n}=13)$ & $490.50 \pm 109.71$ & \\
Female $(n=4)$ & $499.50 \pm 130.95$ & \\
Disability rating & & \\
$1(n=4)$ & $363.50 \pm 49.89$ & \\
$2(n=6)$ & $453.17 \pm 35.18$ & \\
$3(n=7)$ & $599.47 \pm 110.72$ & \\
\hline
\end{tabular}

$\mathrm{SD}$, standard deviation.

${ }^{*} P<0.05$.

\section{RESULTS}

Differences in physical activity levels according to general characteristics

Subjects' average age was 29.88, and 13 men and 4 women participated. The women's physical activity level was higher, at $674.50 \mathrm{kcal}$ for women compared to $649.51 \mathrm{kcal}$ for men, but no significant difference was found. Those with a disability rating of level 3 showed the most activity at $785.29 \mathrm{kcal}$, followed by $598.50 \mathrm{kcal}$ in those at level 2 and $513.50 \mathrm{kcal}$ at level 1, showing more activity among people with a higher disability rating $(P<0.001)$ (Table 1).

\section{Participants' physical activity, physical fitness, and} metabolic syndrome indices

The average daily activity by subjects was $655.41 \mathrm{kcal}$ with levels from $462 \mathrm{kcal}$ to $875 \mathrm{kcal}$ recorded, and the average total physical activity for 5 days was $3,224.94 \mathrm{kcal}$, with levels from $2,244 \mathrm{kcal}$ to $4,255 \mathrm{kcal}$ recorded. The average grip strength was $12.35 \pm 2.89 \mathrm{~kg}$, average sit-up count was $12.41 \pm 5.5$ times, average flexibility was $2.67 \pm 5.72 \mathrm{~cm}$, and average cardiovascular endurance was $17.24 \pm 8.58$ times.

The average total cholesterol was $152.71 \mathrm{mg} / \mathrm{dL}$, and the average $\mathrm{HbA}_{1 \mathrm{c}}$ was $5.94 \%$ (Table 2).

\section{Correlation between physical activity, physical fitness, and metabolic syndrome indices}

Based on the correlation between subjects' physical activity with their physical fitness and metabolic syndrome indices (Table 3), physical activity was positively correlated with disability rating $(P<0.001)$, muscular strength $(P<0.009)$, muscular endurance

Table 2. Description of behavioral and biochemical variables in disabled persons

\begin{tabular}{lcc}
\hline Characteristic & Mean $\pm \mathrm{SD}$ & Observed range \\
\hline Daily activity (kcal/day) & $492.47 \pm 110.72$ & $301-675$ \\
Muscle strength (kg) & $12.35 \pm 2.89$ & $7-17$ \\
Muscle endurance (time) & $12.41 \pm 5.50$ & $3-24$ \\
Flexibility (cm) & $2.67 \pm 5.72$ & $-7.00-13.00$ \\
Cardiovascular endurance (time) & $17.24 \pm 8.58$ & $7-32$ \\
$\mathrm{TC}$ (mg/dL) & $186.729 \pm 15.27$ & $170-216$ \\
$\mathrm{HDL}-\mathrm{C}(\mathrm{mg} / \mathrm{dL})$ & $45.35 \pm 3.55$ & $40-55$ \\
$\mathrm{LDL}-\mathrm{C}(\mathrm{mg} / \mathrm{dL})$ & $138.47 \pm 13.62$ & $110-163$ \\
$\mathrm{HbA} \mathrm{Al}_{1 \mathrm{c}}(\%)$ & $5.94 \pm 0.70$ & $4.80-7.50$ \\
\hline
\end{tabular}

SD, standard deviation; TC, total cholesterol; HDL-C, high density lipoprotein cholesterol; LDL-C, low density lipoprotein cholesterol; $\mathrm{HbA}_{1 \mathrm{c}}$, glycated hemoglobin. 
Table 3. Correlations between daily activity and behavioral and biochemical variables in disabled people

\begin{tabular}{|c|c|c|c|c|c|c|c|c|c|c|}
\hline Variable & Daily activity & $\begin{array}{l}\text { Degree of } \\
\text { disability }\end{array}$ & $\begin{array}{l}\text { Muscle } \\
\text { strength }\end{array}$ & $\begin{array}{c}\text { Muscle } \\
\text { endurance }\end{array}$ & Flexibility & $\begin{array}{c}\text { Cardiac } \\
\text { endurance }\end{array}$ & $\mathrm{TC}$ & LDL-C & HDL-C & $\mathrm{HbA} A_{1 \mathrm{c}}$ \\
\hline Daily activity & 1 & & & & & & & & & \\
\hline Degree of disability & $0.001^{*}$ & 1 & & & & & & & & \\
\hline Muscle strength & $0.009^{*}$ & $0.002^{*}$ & 1 & & & & & & & \\
\hline Muscle endurance & $0.035^{*}$ & $0.004^{*}$ & $0.023^{*}$ & 1 & & & & & & \\
\hline Flexibility & 0.702 & 0.858 & 0.963 & 0.464 & 1 & & & & & \\
\hline Cardiac endurance & 0.431 & 0.645 & 0.553 & 0.585 & 0.735 & 1 & & & & \\
\hline TC & $0.034^{*}$ & $0.010^{*}$ & 0.149 & $0.003^{*}$ & $0.026^{*}$ & 0.714 & 1 & & & \\
\hline HDL-C & 0.309 & 0.146 & 0.182 & $0.017^{*}$ & 0.226 & 0.890 & $0.013^{*}$ & 1 & & \\
\hline LDL-C & $0.034^{*}$ & $0.032^{*}$ & 0.298 & 0.188 & $0.026^{*}$ & 0.644 & $0.002^{*}$ & 0.104 & 1 & \\
\hline $\mathrm{HbA}_{1 \mathrm{c}}$ & 0.318 & 0.081 & $0.021^{*}$ & 0.270 & 0.233 & 0.669 & 0.637 & 0.943 & 0.676 & 1 \\
\hline
\end{tabular}

TC, total cholesterol; HDL-C, high density lipoprotein cholesterol; LDL-C, low density lipoprotein cholesterol; HbA ${ }^{*} P<0.05$.

$(P<0.035)$, total cholesterol $(P<0.034)$, and LDL-C $(P<0.034)$.

\section{Variables that predict physical activity in disabled people}

Stepwise multiple regression analysis was performed to examine the variables that predict physical activity, and nominal variables were processed and analyzed as dummy variables. Independent variables used in regression analysis included disability rating, physical fitness, and metabolic syndrome factors.

Stepwise multiple regression analysis showed that variables that predict physical activity were disability rating $(t=6.28, P<0.001)$ and $\mathrm{HbA}_{1 \mathrm{c}}(t=-2.31, P<0.036)$, and these variables were $73.9 \%$ $\left(R^{2}=0.739\right)$ correlated with the physical activity level of disabled people (Table 4).

\section{DISCUSSION}

This study was conducted with subjects at a sheltered workshop in Uiwang to examine the relationship between the physical activity level of adults over 18 with disabilities and their physical fitness and metabolic syndrome risk factors.

Subjects' physical activity was determined to be $492.47 \pm 110.72$ $\mathrm{kcal}$, which was less than that of children with intellectual disabilities (average age, 11.1), which was $645.85 \pm 104.99 \mathrm{kcal}$ (Kang and Park, 2012), and that of the elderly, which was $628.45 \mathrm{kcal}$ (Sung, 2011). The highest physical activity level, $675 \mathrm{kcal}$, was similar to that of the elderly, and the lowest activity level (301 kcal) was observed in adults with a level 1 disability rating, who also showed the lowest muscular strength and muscular endurance as well.

A significant difference was found between subjects' demographic variables and activity level $(P<0.001)$, but not between
Table 4. Variables predicting daily activity in disabled people

\begin{tabular}{lcccc}
\hline Variable & $\beta$ & $R^{2}$ & $t$ & $P$ \\
\hline Degree of disability & 0.857 & 0.136 & 6.280 & $0.000^{*}$ \\
$\mathrm{HbA}_{1 \mathrm{c}}$ & -0.362 & 0.156 & -2.315 & $0.036^{*}$ \\
\hline
\end{tabular}

$R^{2}=0.739, F=19.826, P<0.001$.

$\mathrm{HbA}_{1 \mathrm{c}}$, glycated hemoglobin.

${ }^{*} P<0.05$

age or BMI.

Muscular strength and muscular endurance showed a similar correlation with physical activity. Increasing physical activity had positive effects on different factors that improve physical strength (Keadle et al., 2017; Nelson et al., 2007), and in 2007 by American College of Sports Medicine recommends mild and high-intensity physical activity for $30 \mathrm{~min}$ or more daily for over 5 days a week (Haskell et al., 2007). Therefore, more interventions to induce more active physical movement for adults with intellectual disabilities are needed. A study has reported that improving basic physical strength in adults with disabilities through walking and stretching led to improved work performance and behavior such as assembly, packaging, and carrying, while increasing power of command and grasp step by step improved their physical function, job behavior, and socialization (Stancliffe and Anderson, 2017).

People with disabilities face difficulty in daily activities and therefore avoid movement and become physically inactive, and their weight and metabolic syndrome frequency increase because they cannot participate in the amount of physical activity required by nondisabled adults (Carroll et al., 2014).

In this study, total cholesterol, the metabolic syndrome index, was determined to be $186.729 \pm 15.27 \mathrm{mg} / \mathrm{dL}$, LDL-C $138.47 \pm$ 
$13.62 \mathrm{mg} / \mathrm{dL}$, HDL-C $45.35 \pm 3.55 \mathrm{mg} / \mathrm{dL}$, and $\mathrm{HbA}_{\mathrm{lc}}(\%)$ $5.94 \% \pm 0.70 \%$. Total cholesterol and LDL-C were significantly correlated with physical activity.

According to a previous study, people with physical disability are reported to have approximately 1.2-13.9 times greater risk of metabolic syndrome (Liou et al., 2005). As seen in this study, physical activity level among adults with intellectual disabilities is relatively lower than among those with no disabilities, and this low physical activity level very likely leads to metabolic syndrome and related chronic disease if it is maintained into adulthood. In fact, the prevalence of chronic disease among disabled people is $77.2 \%$, which is more than twice as high as that of the nondisabled (34.9\%); metabolic syndrome and diseases that affect physical activity such as hypertension and diabetes in particular are more common (Jo et al., 2018). Using multiple regression analysis, this study found that disability rating and $\mathrm{HbA}_{1 \mathrm{c}}$ had an especially significant influence. Diseases that result in lower physical activity level pose higher risks to disabled people, but studies of this phenomenon are critically insufficient. Observing the changes in the health of disabled people is very important in preventing diseases. The development and application of programs to continuously increase the physical activities of adults with intellectual disabilities are urgently needed.

\section{CONFLICT OF INTEREST}

No potential conflict of interest relevant to this article was reported.

\section{ACKNOWLEDGMENTS}

This work was supported by the Ministry of Education of the Republic of Korea and the National Research Foundation of Korea (NRF-2016S1A5B6913737).

\section{REFERENCES}

Carroll DD, Courtney-Long EA, Stevens AC, Sloan ML, Lullo C, Visser SN, Fox MH, Armour BS, Campbell VA, Brown DR, Dorn JM; Centers for Disease Control and Prevention (CDC). Vital signs: disability and physical activity--United States, 2009-2012. MMWR Morb Mortal Wkly Rep 2014;63:407-413.

Cervantes CM, Porretta DL. Physical activity measurement among individuals with disabilities: a literature review. Adapt Phys Activ Q 2010; 27:173-190.
Dixon-Ibarra A, Lee M, Dugala A. Physical activity and sedentary behavior in older adults with intellectual disabilities: a comparative study. Adapt Phys Activ Q 2013;30:1-19.

Fernandes RR, Nabuco HCG, Sugihara Junior P, Cavalcante EF, Fabro PMC, Tomeleri CM, Ribeiro AS, Barbosa DS, Venturini D, Schoenfeld BJ, Cyrino ES. Effect of protein intake beyond habitual intakes following resistance training on cardiometabolic risk disease parameters in pre-conditioned older women. Exp Gerontol 2018;110:9-14.

Frey GC, Stanish HI, Temple VA. Physical activity of youth with intellectual disability: review and research agenda. Adapt Phys Activ Q 2008; 25:95-117.

Giordano U, Turchetta A, Giannotti A, Digilio MC, Virgilii F, Calzolari A. Exercise testing and 24-hour ambulatory blood pressure monitoring in children with Williams syndrome. Pediatr Cardiol 2001;22:509-511.

Haider SI, Ansari Z, Vaughan L, Matters H, Emerson E. Health and wellbeing of Victorian adults with intellectual disability compared to the general Victorian population. Res Dev Disabil 2013;34:4034-4042.

Hartman E, Smith J, Westendorp M, Visscher C. Development of physical fitness in children with intellectual disabilities. J Intellect Disabil Res 2015;59:439-449.

Haskell WL, Lee IM, Pate RR, Powell KE, Blair SN, Franklin BA, Macera CA, Heath GW, Thompson PD, Bauman A. Physical activity and public health: updated recommendation for adults from the American College of Sports Medicine and the American Heart Association. Med Sci Sports Exerc 2007;39:1423-1434.

Jo G, Rossow-Kimball B, Lee Y. Effects of 12-week combined exercise program on self-efficacy, physical activity level, and health related physical fitness of adults with intellectual disability. J Exerc Rehabil 2018; 14:175-182

Kang SY, Park JH. Study on physical activity kevel and blood lipid in intellectual disabled children. Korea J Phys Edu 2012:51;487-493.

Keadle SK, Conroy DE, Buman MP, Dunstan DW, Matthews CE. Targeting reductions in sitting time to increase physical activity and improve health. Med Sci Sports Exerc 2017;49:1572-1582.

Liou TH, Pi-Sunyer FX, Laferrère B. Physical disability and obesity. Nutr Rev 2005;63:321-331.

Ministry of Health and Welfare. Disability stats [Internet]. Deajeon (Korea): Ministry of Health and Welfare; c2018 [cited 2018 Apr 10]. Available from: http://www.index.go.kr/potal/main/EachDtlPageDetail. do?idx_cd=2768.

Moss SJ, Czyz SH. Level of agreement between physical activity levels measured by ActiHeart and the International Physical Activity Questionnaire in persons with intellectual disability. Disabil Rehabil 2018; 40:360-366

Nelson ME, Rejeski WJ, Blair SN, Duncan PW, Judge JO, King AC, Mac- 
era CA, Castaneda-Sceppa C. Physical activity and public health in older adults: recommendation from the American College of Sports Medicine and the American Heart Association. Med Sci Sports Exerc 2007;39:1435-1445.

Stancliffe RJ, Anderson LL. Factors associated with meeting physical activity guidelines by adults with intellectual and developmental dis- abilities. Res Dev Disabil 2017;62:1-14.

Sung KW. Relationship of daily activity and biochemical variables in the elderly with diabetes mellitus. J Korean Acad Nurs 2011;41:182-190.

Taylor D. Physical activity is medicine for older adults. Postgrad Med J 2014;90:26-32. 